\title{
A oclusiva glotal e outros gestos laríngeos na produção de falantes de inglês como L1 e L2
}

\author{
Mariane dos Santos Monteiro Duarte ${ }^{\mathrm{i}}$ \\ Leônidas Silva Jr. ${ }^{\text {ii }}$
}

\section{RESUMO}

O presente trabalho tem como objetivo investigar a produção da oclusiva glotal [?] em substituição da oclusiva alveolar t/ por falantes de inglês como L1 e L2, em palavras como: "cotton" (algodão), que pode ser produzida como co[t]on ou co[?]on. Nossa fundamentação teórica se baseia em estudos como os de Lima-Gregio (2011) e Garellek (2015), sobre processos acústico-articulatórios da oclusiva glotal e gestos laríngeos; Balas (2012), quanto à produção de tais processos em inglês/L2. Na Metodologia, coletamos dados de falantes de inglês/L1 e L2 por meio de leitura de texto e enunciados e, posteriormente, realizamos análise acústica e estatística desses dados. Nossos resultados apontam que a produção da oclusiva glotal é bastante recorrente entre nativos de inglês e significativamente menor entre brasileiros. Ademais, nos deparamos com outros gestos fonéticos para ambos os grupos: laringalização e reforço glotal e, apenas para os brasileiros, o apagamento da oclusiva alveolar.

Palavras-chave: Oclusiva glotal; Oclusiva alveolar; Gestos Laríngeos; Inglês como L2.

\begin{abstract}
This paper aims to investigate the glottal stop [?] production when it takes the place of the alveolar /t/ by L1 and L2 English speakers as in "cotton" co[t]on or co[?]on. Our theoretical framework is grounded on studies such as Lima-Gregio (2011) and Garellek (2015) on acoustic-articulatory processes of the glottal stop and laryngeal gestures;
\end{abstract}

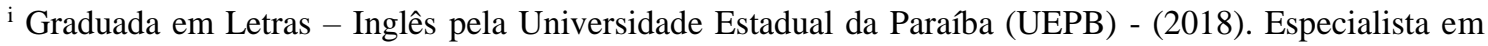
Ensino de Línguas pela UEPB (2020) e Mestranda pelo Programa de Pós-Graduação em Linguística da Universidade Federal da Paraíba (PROLING/UFPB). E-mail: mary4vr@gmail.com. ORCID: https://orcid.org/0000-0002-8127-5051.

O presente trabalho foi realizado com apoio da Coordenação de Aperfeiçoamento de Pessoal de Nível Superior - Brasil (CAPES) - Código de Financiamento: 88887.497814/2020-00.

ii Doutor em Linguística pelo Programa de Pós-Graduação em Linguística na Universidade Federal da Paraíba - PROLING/UFPB (2013). Tem Pós-Doutorado em Fonética experimental com ênfase em Prosódia de L2 pelo Instituto de Estudos da Linguagem na Universidade Estadual de Campinas /IEL/UNICAMP (2019). Atualmente é Professor Adjunto 3 na Universidade Estadual da Paraíba (UEPB) e Pesquisador Assistente de Pós-Doutorado em Fonética experimental pelo Instituto de Estudos da Linguagem na Universidade Estadual de Campinas (IEL/UNICAMP) com ênfase em Análise fonéticoforense a partir da Prosódia de L2. E-mail: leonidas.silvajr@gmail.com. ORCID: http://orcid.org/00000002-3728-9851.

O presente trabalho foi realizado com apoio do Conselho Nacional de Desenvolvimento Científico e Tecnológico (CNPq) - Código de Financiamento: 150143/2018-4.
} 
Balas (2012) on the production of these processes in L2. As for the methods, we collected data from English/L1 and L2 speakers through text reading and utterances; thereafter, we held acoustic and statistical analisys from the data. Our results pointed out to the glottal stop production as being a quite recurrent phenomenon among native English speakers and a significantly lower one among Brazilians. In addition, our findings pointed out to other phonetic gestures such as laryngealization and glottal reinforcement (for both groups), and alveolar deletion (for Brazilians only).

Keywords: Glottal stop; Alveolar stop; Laryngeal Gestures; English as L2.

\section{INTRODUÇÃO}

O inglês, assim como as outras línguas, apresenta particularidades fonéticoarticulatórias e, dessa forma, o fato de apenas conhecer questões no domínio da morfossintaxe da língua estrangeira (doravante, L2) ${ }^{1}$ não é suficiente para que ocorra uma comunicação fluida e inteligível. As habilidades fonético-articulatórias, por vezes, desafiam o aprendiz de inglês como L2, dado que a língua inglesa (doravante, LI) difere bastante do português brasileiro (doravante, PB); desde as suas relações grafo-fônicas ao seu modelo articulatório, tanto no nível segmental (segmentos isomórficos ao fonema), quanto no prosódico (aplicação de acento léxico-frasal e realização de ritmo e entonação).

À vista disso, é comum que haja um estranhamento por parte do aprendiz ao se deparar com os sons da L2 que não fazem parte da sua língua materna (doravante, L1), bem como dificuldades em alcançar a produção destes. Assim, a não consciência dos aspectos sonoros da L2 pode trazer complexidades tanto na produção como na percepção da língua-alvo, conforme aponta o estudo seminal de Selinker (1972), quando da Teoria da Interlíngua e da percepção-produção de novas categorias fonéticas, bem como Flege (1988), quando do estabelecimento do Modelo de aprendizado de Fala (speech learning model - SLM), em que o foco da investigação linguística deve levar em consideração a produção e a percepção do aprendiz de L2, porque a produção acurada está fortemente correlacionada à percepção dos sons desta L2-alvo. Diante desse cenário, percebe-se que a fonética desempenha um papel relevante no processo de aprendizagem de inglês como L2, o que torna o seu conhecimento indissociável dos demais elementos de uma língua. 
Nessa perspectiva, podemos citar um som bastante recorrente entre nativos de inglês, a saber: a oclusiva glotal (glottal stop), como destacam Garellek (2015) e Faris (2010). Esse som, também conhecido como glotalização (glottalization), é um alofone existente na LI (OGDEN, 2009), produzido pela adução (fechamento) e abdução (abertura) das pregas vocais. Sendo assim, sua realização se dá em uma região interna do trato vocal: na glote.

Como bem aponta Ogden (2009), a oclusiva glotal é caracterizada como um alofone da oclusiva alveolar (alveolar stop), uma vez que aquela pode substituir esta sem que haja mudança no significado da palavra, como em: cotton (algodão) que pode ser produzida com uma oclusiva alveolar: $c o[t]$ on ou com uma oclusiva glotal: $c o[?]$ on. Nesse sentido, quando o falante permuta a alveolar pela glotal, estamos diante do fenômeno chamado de glotalização-t (t-glottalization), em consonância com Faris (2010), Garellek (2015) e Cobacho (2018).

De acordo com os três últimos autores mencionados no parágrafo anterior, a oclusiva glotal é muito comum entre falantes nativos da LI e bastante recorrente em suas variedades mais conhecidas como o inglês americano (Estados Unidos e Canadá), britânico, irlandês, escocês, australiano e neozelandês. Já Duarte (2018) destaca que a oclusiva glotal é um som que dificilmente é conhecido por aprendizes brasileiros de inglês/L2, uma vez que, além de não fazer parte do inventário fonológico do PB, é, ainda, pouco discutido no Brasil. Além disso, a autora (op. cit.) indica que a oclusiva glotal é complexa para os brasileiros falantes de inglês/L2, seja no tocante à sua produção, por ser um segmento posterior produzido na região laríngea, seja no que concerne à sua percepção, por ser um som que não está presente no inventário fonológico do PB.

Cientes disso, objetivamos verificar se brasileiros aprendizes de inglês/L2 apresentam dificuldades em produzir a oclusiva glotal enquanto alofone da oclusiva alveolar, bem como averiguar se, em detrimento da oclusiva alveolar, há a realização de outros gestos fonéticos para a substituição desta.

Diante do exposto, testaremos a seguinte hipótese: falantes brasileiros de inglês/L2 têm dificuldades na realização do fenômeno de glotalização-t no inglês, uma vez que a oclusiva glotal, além de não estar presente no PB como alofone da oclusiva alveolar (nem tampouco de outras oclusivas), possui como características acústicas 
queda da frequência fundamental e da intensidade e maior duração da janela espectral, as quais contribuem para produção de outras categorias fonéticas, inclusive para o apagamento da oclusiva alveolar.

Destarte, a justificativa para a temática do presente artigo é a de que, uma vez que se trata de um segmento que não é comum à percepção-produção dos aprendizes brasileiros de inglês, é possível auxiliar professores e aprendizes a compreender melhor as dificuldades na produção da oclusiva glotal. Além disso, trata-se de uma categoria fonética bastante recorrente no inglês como já fora explicitado, todavia, pouco investigada pela literatura fonético-experimental no Brasil. Assim, percebemos, no âmbito nacional, a carência de trabalhos que analisem o segmento-alvo no processo de aprendizagem de inglês/L2, e a necessidade de ampliar os estudos concernentes ao fenômeno, a fim de colaborar com as áreas de Fonética e Fonologia de L2 e/interlíngua, bem com o ensino de inglês/L2.

Este artigo está dividido nas seguintes seções: Introdução; seção 2 Fundamentação Teórica, em que abordamos características acústico-articulatórias da oclusiva glotal e alveolar, bem como os ambientes fonológicos para a realização da oclusiva glotal, tanto no domínio segmental como no prosódico, além de uma revisão bibliográfica de trabalhos que tratam da oclusiva glotal no inglês/L2; seção 3 Metodologia, em que mostramos a constituição de nosso corpus, escolha dos participantes, além de como se deu coleta de dados, seguido dos tratamentos acústico e estatístico destes; seção 4 - Resultados e Discussão, em que apresentamos os resultados acústicos e estatísticos, bem como uma discussão destes na tentativa de identificar/responder os porquês de cada grupo ter um comportamento distinto frente aos dados. Por fim, as considerações finais de nossa pesquisa, seguidas das referências utilizadas.

\section{FUNDAMENTAÇÃO TEÓRICA}

Nesta seção, apontaremos uma revisão da literatura acerca das características acústico-articulatórias dos segmentos: oclusiva glotal e alveolar, bem como os ambientes propícios à realização da oclusiva glotal, além de um levantamento bibliográfico de trabalhos que tratam da produção da oclusiva glotal no inglês/L2. 


\subsection{Características acústico-articulatórias da oclusiva glotal e da oclusiva alveolar}

Marino, Berti e Lima-Gregio (2013, p. 467), no tocante ao processo articulatório da oclusiva glotal, destacam que a sua produção é "[...] resultante da adução das pregas vocais, devido a um aumento de pressão aérea gerada na região subglótica e consequente tensão na região mais baixa do trato vocal, seguida de intensa abertura e fechamento das pregas vocais".

Faris (2010) descreve três etapas para a produção da oclusiva glotal, conforme mostra a Figura 1:

1. Aproximação (approach): momento em que o fluxo de ar é impedido pelo fechamento das pregas vocais;

2. Mantimento (hold): momento em que as pregas vocais se mantêm fechadas, a fim de obstruir completamente o fluxo de ar;

3. Soltura (release): momento em que o fluxo de ar é liberado pela abertura das pregas vocais.

Figura 1: Visualização das pregas vocais na fase da aproximação, fechamento brusco e mantimento (destaque em verde), seguido da abertura destas (realce em amarelo).

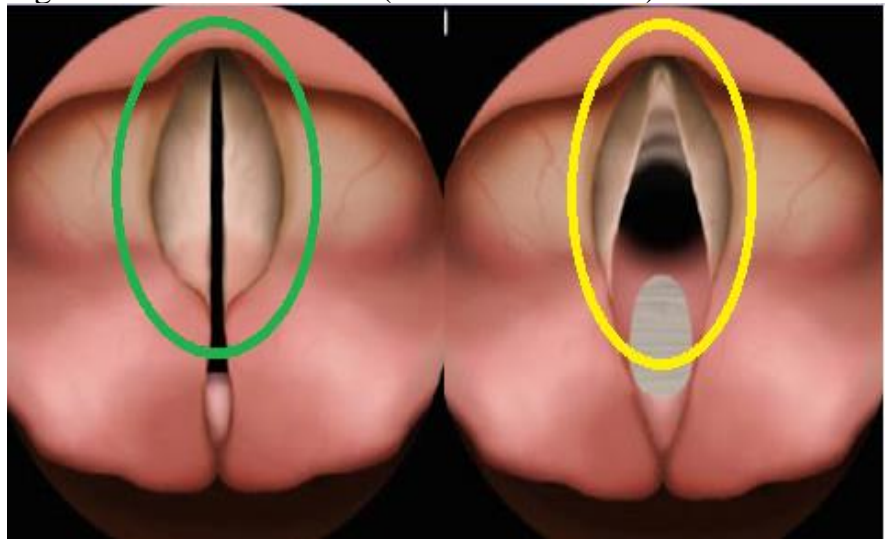

Fonte: Adaptado de: <http://www.laringocenter.com.br/paralisia-de-cordas-vocais/>.

Quanto à natureza articulatória, a oclusiva glotal é um som que se realiza na cavidade posterior do trato vocal (na laringe), mais especificamente na glote. A literatura fonética já observa o comportamento deste segmento há quase um século. Desde os estudos de Stetson ([1928], 1951) até os atuais (Hussien-Seid, 2011; Garellek \& Seyfarth, 2016, dentre outros) apontam que na produção da oclusiva glotal, a glote se 
mantém fechada, e a laringe se move em direção ao trato vocal a fim de criar uma pressão para a realização do fenômeno de glotalização.

No que tange às características acústicas, destacamos que a oclusiva glotal é um som de natureza acústica com Frequência Fundamental (doravante, F0) e intensidade baixa, como indicam Cobacho (2018) e Garellek (2015). Consoante Duarte (2018), a F0 é inversamente proporcional à duração, isto é, uma lenta vibração das pregas vocais apresenta maior duração dos pulsos glotais (de 10 a 16 milissegundos), o que resulta em baixa F0. Em contrapartida, uma rápida vibração das pregas vocais (05 milissegundos que é a forma padrão) possui menor duração dos pulsos glotais, resultando, assim, em um alto valor para F0. Vejamos a Figura 2, para entendermos as características acústicoarticulatórias da oclusiva glotal e oclusiva alveolar.

Figura 2: Porção à esquerda: forma de onda, espectrograma de banda larga, contorno de F0 (em azul) na produção da palavra "cotton" (algodão), com oclusiva glotal [?] (contorno em vermelho), por um falante do grupo dos nativos. Porção à direita: forma de onda, espectrograma de banda larga na produção da palavra "cotton" com oclusiva alveolar (contorno em verde) por um falante do grupo dos brasileiros [t].
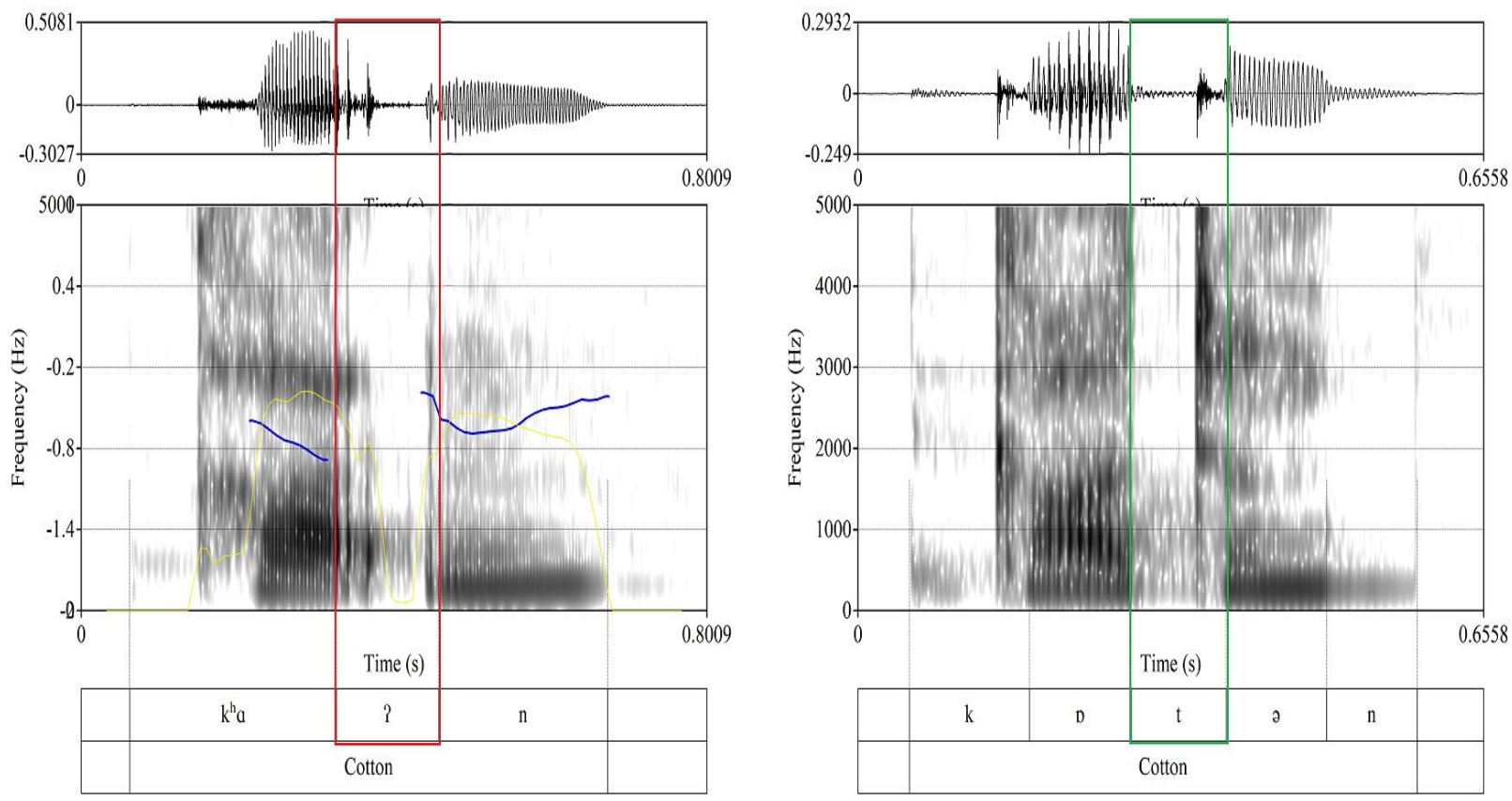

Fonte: os autores (2020).

A observação da realização do segmento-alvo ocorre de acordo com o protocolo de Garellek \& Seyfarth (2016), em que a análise deve ser feita a partir do $3^{\circ}$ terço da vogal da sílaba anterior à produção glotal, isto é, no final da produção nuclear. Assim, analisando o som vocálico [a], na palavra “cottton” precedente à oclusiva glotal (cf. 
porção à esquerda na Figura 2), percebe-se que há uma desaceleração dos pulsos glotais com duração $=05$ milissegundos (duração default de abertura e fechamento da glote na voz normal), se comparados aos pulsos glotais no momento da produção glotal.

Já na produção da oclusiva alveolar, (imagem da porção direita da Figura 2), assim como aponta Duarte (2018), não há presença de pulsos glotais, uma vez que se trata de um som não vozeado. Assim, em sua realização, percebe-se um silêncio (representado pelo aprisionamento das frequências) seguido de zona de transiência e soltura (concentração de energia observada no espectrograma de banda larga pela tonalidade escura de cinza e na forma de onda pela pressão sonora local), conforme explicado por Barbosa e Madureira (2015).

\subsection{Ambientes para a realização da oclusiva glotal}

Como colocado anteriormente, a oclusiva glotal se caracteriza como um alofone na LI, uma vez que esta pode substituir a produção da oclusiva alveolar sem que cause mudança de significado da palavra, como em: "important” [Importənt] $\rightarrow$ [Impor?n?],

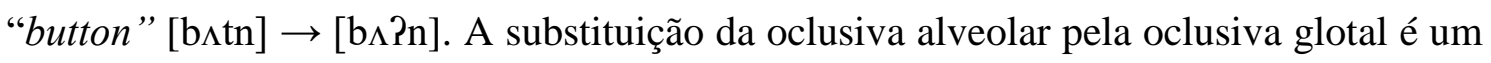
processo denominado de glotalização-t ( $t$-glotalization) (GARELLEK \& SEYFARTH, 2016; COBACHO, 2018). De acordo com Faris (2010) e Cobacho (op. cit.), o fenômeno de glotalização-t, no inglês Americano, pode ocorrer nos seguintes ambientes fonológicos e/ou prosódicos na interface fonologia-sintaxe:

Antes de oclusivas orais e nasais em que: i) suaviza o Redobramento Sintático (raddoppiamento sintatico - cf. Nespor \& Vogel, 1986, 2007) em coda final do elemento-cabeça seguido do elemento-complemento em um mesmo sintagma fonológico, ou em: ii) elementos de uma string précabeça em um mesmo sintagma fonológico, e em: iii) elementos de uma string pós-cabeça em um mesmo sintagma fonológico.

- Orais: i) get time [ge?tarm]; ii) quite good breakfast [kwar?god];

- Nasais: i) that name [ðæ?neIm]; iii) look at me [lokə? mi];

No ataque de sílaba pós-tônica em que há traço de nasalidade na posição

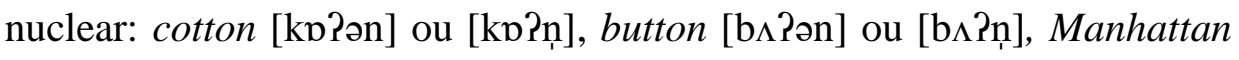
[mænhæ?ən] ou [mænhæ?n]]; 
Em posição de coda em que o som precedente à produção glotal tenha traço de sonoridade: that [ðæ?], out [að?].

Vale a pena ressaltar, assim como destacam Eddington \& Taylor (2009), que o ambiente fonológico propício à realização da glotalização-t pode mudar a depender da variedade do inglês. Nessa perspectiva, Cobacho (2018) faz menção ao dialeto conhecido como "Cockney English", falado em Londres, e aponta para mais um ambiente favorável à produção da oclusiva glotal: o ambiente intervocálico, como em:

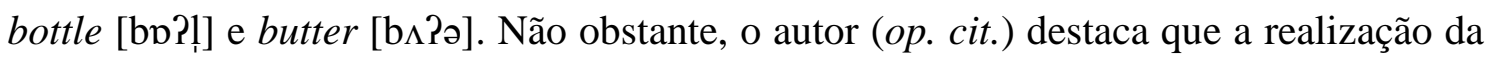
oclusiva glotal entre sons de traço [+ soante] é uma característica marcada do Cockney Enlgish. Em consonância com o autor, Duarte (2018) aponta que, em ambientes intervocálicos, falantes nativos do inglês dos Estados Unidos, tendem a produzir o fenômeno de flapping no lugar da oclusiva alveolar, como em: better [berər], bottle [bprl] e butter [bırər].

\subsection{A oclusiva glotal no inglês/L2}

Por meio do levantamento bibliográfico concernente ao nosso objeto de estudo, nos deparamos com o trabalho de Ito e Strange (2009). Os autores avaliaram de modo perceptual a produção oclusiva glotal no início de palavras (oclusiva glotal + vogal) produzidas por falantes japoneses de inglês/L2, os quais tinham tempo considerável de residência nos Estados Unidos. De acordo com os autores, a imersão no país contribuiu significativamente para percepção e produção do segmento-alvo.

Utilizando a mesma L1, o estudo de Shinohara et al. (2011) examinou a percepção da oclusiva glotal em contexto intervocálico no inglês britânico. Os autores concluíram que os japoneses conseguiram diferenciar o referido alofone por meio do parâmetro acústico de Amplitude (ênfase espectral) enquanto os ingleses o fizeram a partir da F0. Vale ressaltar que os japoneses desta pesquisa moraram nos Estados Unidos entre 6 meses e 2 anos, o que ratifica a conclusão de Ito e Strange (op. cit.).

Já Drummond (2011) avalia a produção da oclusiva glotal por falantes poloneses de inglês/L2 como alofone da oclusiva alveolar, processo de glotalização-t. O autor seleciona falantes de nível de proficiência avançado e conclui que: entre produzir a 
oclusiva alveolar e a glotal, o falante polonês produz significativamente mais a oclusiva alveolar, o que corrobora a ideia de Ito \& Strange (2009), Faris (2010), Norton (2017), que a oclusiva glotal é um som complexo para os falantes de inglês/L2. Chamamos atenção para o trabalho de Drummond (2011), já que este buscou avaliar o contraste na produção fonética da "oclusiva glotal vs. alveolar", uma das questões debatidas em nosso trabalho.

Assim como Drummond (op. cit.), o estudo de Balas (2011) avaliou a produção da oclusiva glotal por falantes poloneses proficientes de inglês/L2 e concluiu que os poloneses a produzem tanto em início de palavras (oclusiva + vogal), bem como em sílabas que possuem ditongos de nó [+ fraco]. Vale a pena ressaltar que a oclusiva glotal está presente como um alofone na língua polonesa e, para a autora, é utilizado em início de palavras nativas. Esse fato pode indicar um facilitador na produção do inglês como L2.

No âmbito nacional, a pesquisa piloto de Monteiro \& Silva Jr. (2017) investigou se brasileiros falantes de inglês/L2 apresentam dificuldades na produção da oclusiva glotal. Os autores indicam que o referido som é bastante comum entre falantes nativos da LI e, ao mesmo tempo, um som de articulação complexa para falantes brasileiros de inglês/L2.

Seguindo essa linha, Duarte (2018) e Duarte e Silva Jr. (2019) investigam a oclusiva glotal enquanto alofone da oclusiva alveolar, produzida por falantes brasileiros de inglês/L2 com nível de proficiência intermediário e avançado em cotejo com produções de falantes de inglês como L1. Os autores concluíram que, enquanto os falantes de inglês/L1 realizam significativamente mais oclusiva glotal em detrimento da alveolar, os brasileiros estão na contramão do processo, produzindo significativamente mais oclusiva alveolar do que oclusiva glotal. Segundo os autores, o nível de proficiência não foi um fator significativo para a produção do segmento-alvo.

\section{METODOLOGIA}

A nossa metodologia é de cunho qualitativo e quantitativo. Qualitativo no que tange à análise dos dados que compõem nosso corpus para determinar, sob o ponto de vista fonético-acústico, a realização (ou não) de oclusiva glotal ou alveolar e/ou outro 
tipo de fenômenos laríngeos. Quantitativo no que tange à análise estatística dos dados para determinar, sob o ponto de vista estatístico-probabilístico, como se comportam os grupos que compõem nosso corpus.

\subsection{Constituição do corpus}

\subsubsection{Participantes}

Nossa pesquisa está constituída por seis participantes, os quais estão estratificados por dois grupos; um grupo experimental formado por 4 participantes brasileiros (BRA) aprendizes de inglês/L2, com nível intermediário e um grupo controle formado por 2 norte-americanos falantes nativos de inglês (NAT) oriundos dos Estados Unidos. O nível de proficiência do BRA foi verificado por meio do Oxford Online Placement Test (OOPT), (PURPURA, 2019). O OOPT auxilia no nivelamento do falante para que este seja devidamente inserido em um nível apropriado às suas habilidades no inglês. $\mathrm{O}$ teste leva em conta habilidades orais e interpretativas a partir da leitura de textos (cf. PURPURA, 2019).

No tocante à escolha dos participantes para a nossa pesquisa, optamos pelo nível intermediário de inglês/L2 (B2), uma vez que, de acordo com Purpura (2019), estes aprendizes já teriam um nível suficiente para interações com nativos de inglês em assuntos diversos. O falante, a esta altura, já é capaz de ler relatórios simples, falar sobre tópicos relacionados à família e escrever e-mails simples sobre assuntos de sua área, além de ter a habilidade de lidar com a maioria das situações que podem surgir, ainda que não tenha conhecimento mais amplo do idioma, isto é, em nivel avançado, conforme aponta o autor (op. cit.). O nivel básico, por sua vez, não seria o ideal, uma vez que estes falantes ainda não teriam adiquirido um arcabouço fonético-fonológico suficiente para o desenvolvimento de experiências de oralidade mais amplas na L2-alvo.

\subsubsection{Coleta de dados}

A coleta dos dados foi realizada em um ambiente silencioso, em que apenas permaneceram a pesquisadora e um informante por vez. Para tanto, utilizamos: 
$\checkmark$ Gravador: Zoom H1 Handy PCM Recorder 200m;

$\checkmark$ Microfone: On-board Zoom H1 unidirectional Microphone;

$\checkmark$ Taxa de frequência de resposta do microfone: 30 a $16000 \mathrm{~Hz}$;

$\checkmark$ Taxa de amostragem: $44100 \mathrm{~Hz}$;

$\checkmark$ Taxa de quantização: 16 bits;

$\checkmark$ Ambiente: silencioso com relação sinal-ruído $>30 \mathrm{~dB} .^{2}$

O microfone foi mantido em uma distância de 10 a $15 \mathrm{~cm}$ da boca do participante, a fim de que não houvesse interferência de fatores externos, bem como maior aproveitamento de energia do material coletado em virtude da natureza acústica da oclusiva glotal (cf. seção 2.1 desta pesquisa). Em seguida, os participantes foram submetidos à leitura de um texto, bem como de quinze enunciados - os quais foram apresentados por intermédio de slides pelo MS PowerPoint - contendo a oclusiva alveolar em ambientes propícios ao fenômeno de glotalização-t.

Um total de 85 alvos (palavras e/ou frases contendo os sons a serem produzidos como [t] ou [?]) foi lido pelos grupos. Cada grupo realizou o experimento em duas rodadas distintas, gerando 340 ocorrências por rodada para o BRA ( $85_{\text {alvos }} \mathrm{x} 4$ participantes) e 170 ocorrências por rodada para o NAT ( $\left.85_{\text {alvos }} \mathrm{x} 2_{\text {participantes }}\right)$. Ao todo, obtivemos 680 ocorrências produzidas pelo BRA ( $340_{\text {ocorrências }}$ x $\left.2_{\text {rodadas }}\right)$ e 340 pelo NAT ( $170_{\text {ocorrências }}$ $\mathrm{x} 2$ rodadas). A quantidade absoluta de produções geradas pelas respectivas ocorrências foi de 1020 ocorrências (BRA + NAT).

\subsection{Tratamento acústico dos dados}

O tratamento acústico dos dados foi realizado por meio do programa computacional Praat (BOERSMA \& WEENINK, 2019). Nosso objetivo com o tratamento acústico foi capturar gestos fonéticos tanto pela forma de onda (a pressão sonora dos segmentos), como pelo espectrograma de banda larga (relação de queda/aumento de amplitude/energia ao longo do tempo pelo contraste de cinza).

No que concerne aos fenômenos laríngeos encontrados, utilizamo-nos da análise de decaimento da F0, aumento ou diminuição da amplitude (ênfase espectral) e duração 
da janela espectral (cf. LIMA-GREGIO, 2011; GARELLEK \& SEYFARTH, 2016) e, no que tange às oclusivas alveolares, utilizamos parâmetros de ruído espectral e ruídos de intensidade para a sua detecção (cf. SUNDARA, 2004).

Assim, para a análise acústica, realizamos os seguintes procedimentos:

$\checkmark$ Extraímos as palavras do texto e enunciados que continham um gatilho para a realização dos segmentos-alvo ([t] ou [?]);

$\checkmark$ Em seguida, realizamos a segmentação fonética e a etiquetagem dessas palavras em duas camadas:

- Camada 1: contendo a transcrição fonética da palavra em que o gesto laríngeo e/ou a oclusiva alveolar está em evidência;

○ Camada 2: Transcrição ortográfica da palavra.

Vejamos, a partir da Figura 3, como ocorreram a segmentação e a etiquetagem de nossos dados:

Figura 3: Porção à esquerda: espectrograma de banda larga, contorno de F0 (em azul) e de intensidade (em amarelo) na produção da palavra "cotton" (com a oclusiva glotal) por um falante do grupo NAT. Porção à direita: espectrograma de banda larga na produção da palavra "cotton" (com a oclusiva alveolar) por um falante do grupo BRA.
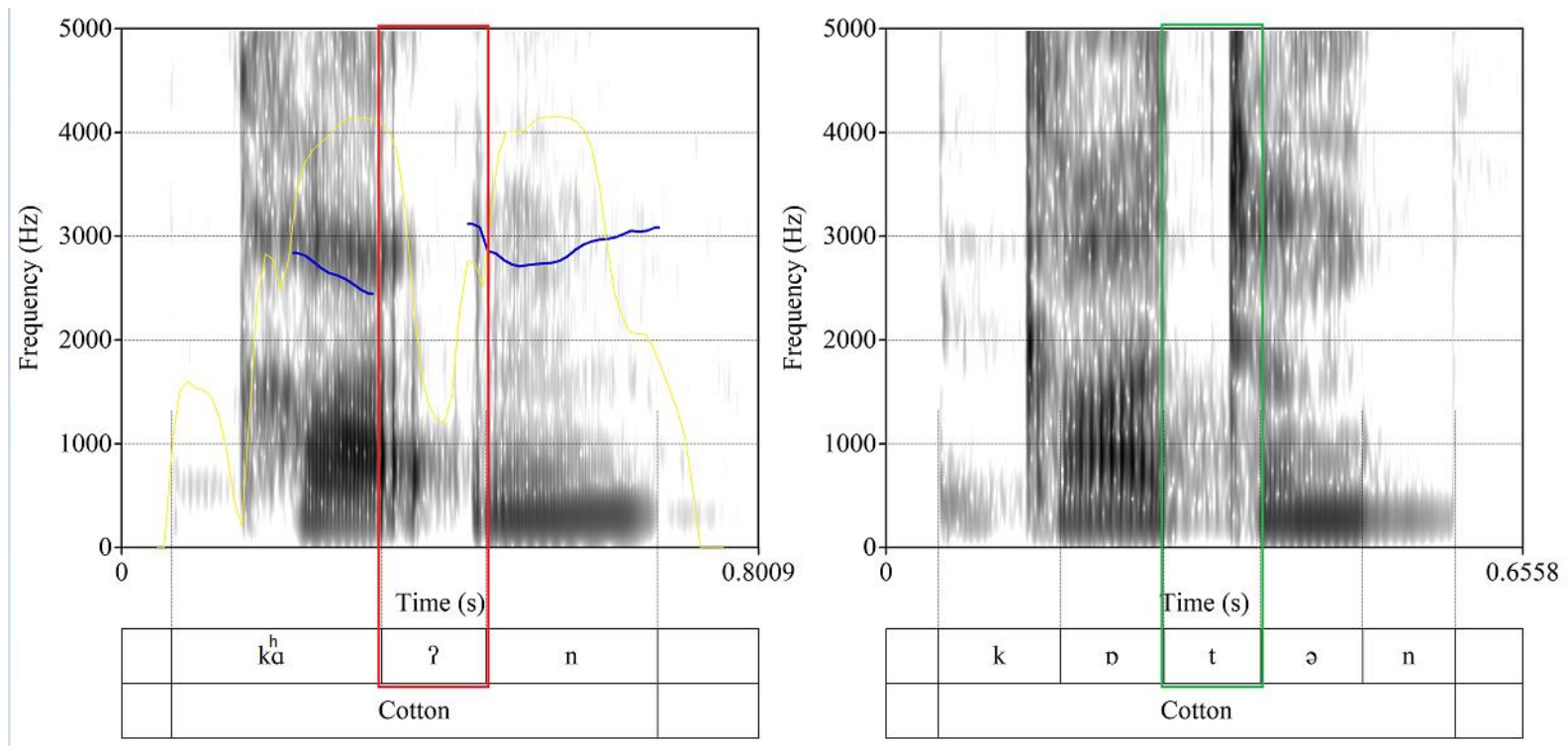

Fonte: os autores

\subsection{Tratamento estatístico dos dados}


O tratamento estatístico de nossos dados foi realizado por meio da Linguagem $\mathrm{R}$ (R Core Team, 2019), disponível em: <https://cran.r-project.org/>, pela técnica estatística de Qui-quadrado. Segundo Triola (2014), essa técnica é usada para verificar se há uma associação entre as variáveis (de linha e coluna) que compõem uma tabela de contingência construída a partir dos dados da amostra. Em outras palavras, e, para nossa pesquisa, queremos observar se há uma associação entre o grupo (nativos ou brasileiros) e a produção realizada por este (se oclusiva glotal, alveolar ou algum outro gesto).

Um valor de significância (alfa) de $5 \%$ foi utilizado para verificar se há variação significativa (ou não) na produção fonética dos fenômenos pelos níveis do grupo. Se alfa $(p$-valor $)<5 \%$, ou seja, $(\mathrm{p}<0,05)$, há variação significativa nos níveis entre os grupos para determinada(s) produção(ões), isto é, nativos e brasileiros produzem um dado (ou mais) fenômeno(s) significativamente diferentes (cf. Tabela 1, "PRODUÇÃO" para os fenômenos).

\section{RESULTADOS E DISCUSSÃO}

Vejamos, na Tabela 1, o resumo de nossos dados a partir do teste de Quiquadrado realizado:

Tabela 1: Estatísticas do Teste de Qui-quadrado em que: PRODUÇÃO = ao tipo de segmento realizado pelos participantes; GRUPO $(\%)=$ a porcentagem $(\%)$ de produções por cada um dos grupos; NAT = falantes nativos de inglês/L1 e BRA = falantes brasileiros de inglês/L2; $\chi^{2}=$ valor do qui-quadrado crítico (calculado pela diferença entre as observações e os dados esperados entre os dois grupos (cf. seção 3.3) e P-VALOR = valor de probabilidade estabelecido em 5\% (cf. seção 3.3)

\begin{tabular}{lccccc}
\hline \multirow{2}{*}{ PRODUÇÃO } & \multicolumn{2}{c}{ GRUPO (\%) } & \multirow{2}{*}{$\chi^{2}$} & P-VALOR \\
& NAT & BRA & & \\
\cline { 2 - 3 } Oclus. glotal & 50,2 & & 3,3 & 40,56 & $<0,001 * * *$ \\
Oclus. alveolar & 19,8 & 82,5 & 38.20 & $<0,001 * * *$ \\
Laringalização & 26,4 & & 3,8 & 16.85 & $<0,001 * * *$ \\
Reforço glotal & 3,6 & 2,2 & 0,63 & $=0,42$ \\
Apagamento & 0,0 & 8,2 & 8,38 & $<0.01 * *$ \\
\hline
\end{tabular}

Fonte: Os autores (2020).

Podemos perceber, a partir da Tabela 1, que os nativos analisados produziram mais a oclusiva glotal do que a oclusiva alveolar. Desse modo, a partir do Gráfico 1, 
verificamos, inicialmente, o comportamento estatístico de ambos os segmentos: oclusiva glotal e oclusiva alveolar, os quais motivaram a nossa pesquisa:

Gráfico 1: Histogramas de distribuição assimétrica positiva; de [?] para os nativos (porção à esquerda com curva em vermelho) e de [t] para os brasileiros (porção à direita com curva em azul).
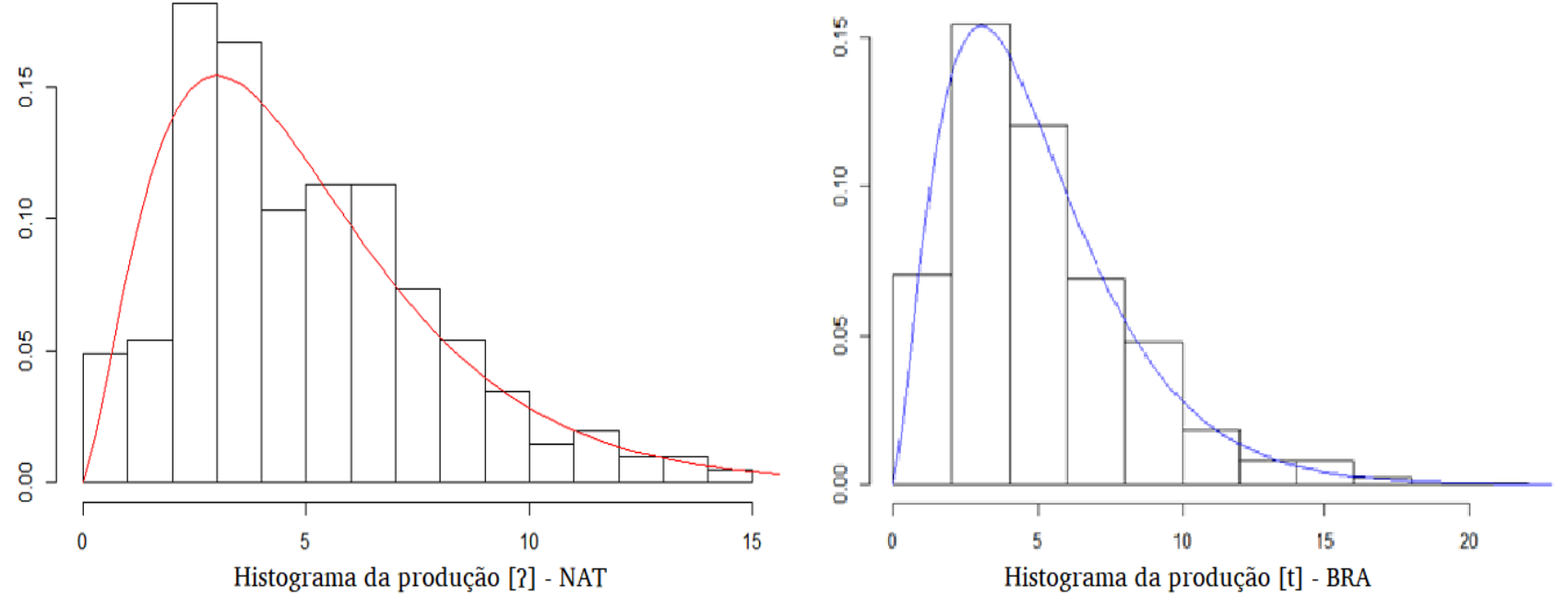

Fonte: Os autores (2020).

Em se tratando de uma comparação entre produções das oclusivas glotal vs. alveolar, o Gráfico 1 indica que o grupo NAT produz significativamente mais oclusivas glotais em contexto de alofonia com oclusiva alveolar do que a própria oclusiva alveolar ou qualquer outro gesto laríngeo. Por outro lado, o grupo dos brasileiros (BRA) produziu, consideravelmente, mais oclusivas alveolares, em detrimento da glotal, do que qualquer outro gesto laríngeo. A assimetria positiva, nos dois casos, indica uma média substancialmente maior na oclusiva glotal (para os nativos) e, em sua contraparte, isto é, na oclusiva alveolar, para os brasileiros.

Assim, no inglês/L1, a oclusiva glotal é bastante recorrente em detrimento da oclusiva alveolar, o que foi possível verificar em nossos dados, o que corrobora as noções levantadas por Garellek \& Seyfarth (2016). Contudo, é notável que o mesmo não ocorre com os falantes brasileiros de inglês/L2. Conforme podemos observar na Tabela 1, há uma produção significativa da oclusiva alveolar por parte dos brasileiros, com $82,5 \%$ contra $3,3 \%$ em relação à oclusiva glotal. Uma das possíveis causas para a não realização da oclusiva glotal, por parte dos brasileiros, pode estar ligada às suas características acústicas: baixa intensidade e F0 e, tendo em vista os baixos valores 
fornecidos por esses parâmetros, não há sincronismo entre o comportamento perceptual e o acústico e, consequentemente, articulatório.

A diminuição de amplitude e da F0 também induz o falante à produção dos gestos laríngeos por nós encontrados durante o tratamento acústico dos dados. Nesse sentido, além da oclusiva glotal, os dois grupos realizaram fenômenos de laringalização e reforço glotal, além do apagamento realizado apenas pelo grupo dos brasileiros. De modo significativo, o grupo NAT, realiza mais laringalização do que o grupo BRA, conforme mostra a Tabela 1. A partir disso, podemos inferir que outros gestos laríngeos, os quais se aproximam da produção da oclusiva glotal, são utilizados em detrimento da oclusiva alveolar, conforme mostra o Gráfico 2.

Gráfico 2: Distribuição de frequência relativa (\%) das ocorrências por categoria de produção entre os nativos e brasileiros.

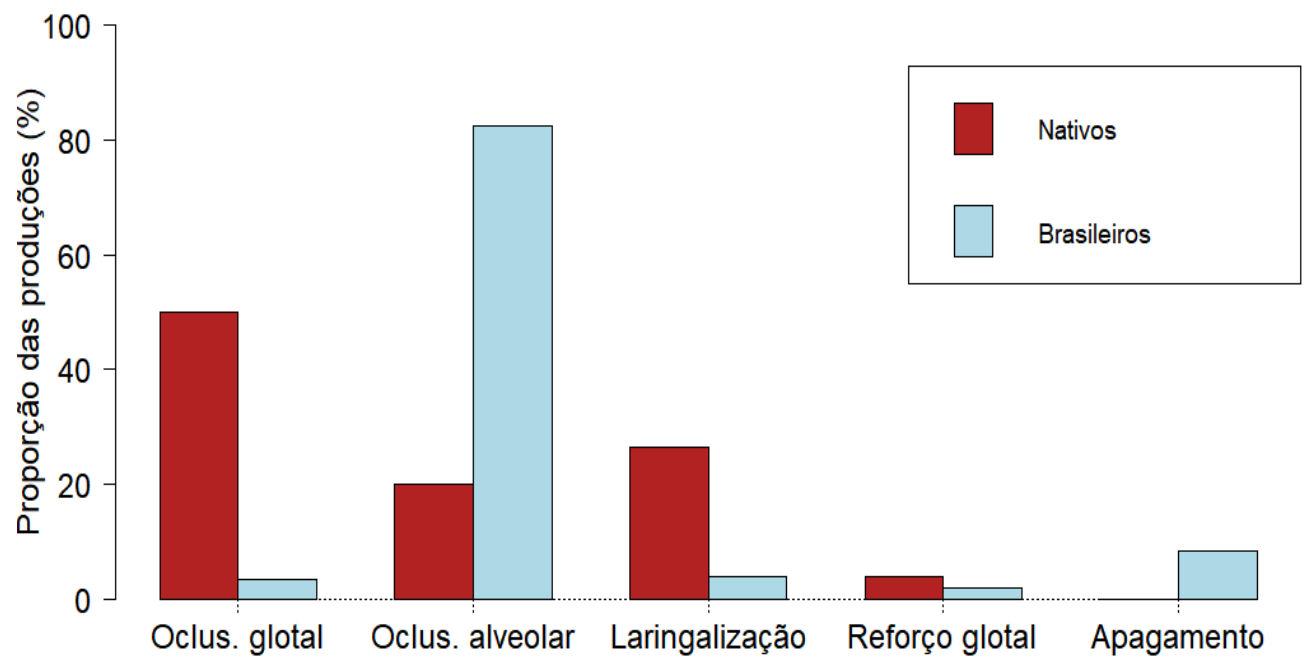

Fonte: os autores (2020).

Percebe-se que houve a produção de reforço glotal entre os pesquisados, porém, a sua realização não se mostrou significativa (cf. Tabela 1; Gráfico 2). O mesmo acontece com a laringalização realizada pelos NAT e BRA, contudo, é notável uma produção maior de laringalização pelo NAT e, de maneira não significativa, pelo BRA. Salientamos, ainda, que a omissão da oclusiva alveolar, isto é, o apagamento sonoro desta, se deu apenas pelo grupo BRA, a qual comentaremos mais adiante.

Analisando as produções, de modo geral, umas das possíveis causas, e que justifica a particularidade dos nossos dados, é a de que, para o grupo NAT, haveria certa preferência pela glotalização e/ou laringalização, por se tratarem de fenômenos 
acoplados, nos quais a pauta articulatória é realizada por intermédio de um mesmo mecanismo (fechamento e abertura da glote), como aponta Lima-Gregio (2011). Essa pauta justificaria os resultados apresentados no Gráfico 2, quanto à glotalização e à laringalização. Entendemos, dessa forma, que a laringalização se apresenta como um fenômeno acoplado à glotalização-t, (cf. LIMA-GREGIO, 2011; GARELLEK, 2015), dado que, a não produção da oclusiva glotal, resulta em uma laringalização vocálica, conforme aponta a Figura 3.

Já para o grupo BRA, a opção é contrária. É preferível a produção da oclusiva alveolar ou, até mesmo, o apagamento desta, conforme o Grafico 2, dado que a alofonia, entre os dois segmentos (oclusiva glotal e alveolar), não ocorre no PB.

Figura 3: Porção à esquerda: forma de onda, espectrograma de banda larga, contorno de F0 (em azul) na produção da palavra "about" (sobre/em relação a), laringalizada no ditongo [av] (contorno em vermelho), por um falante do grupo NAT. Porção à direita: forma de onda, espectrograma de banda larga na produção da palavra "Scotland" (Escócia), laringalizada na vogal [e ] (contorno em verde) por um falante do grupo BRA.
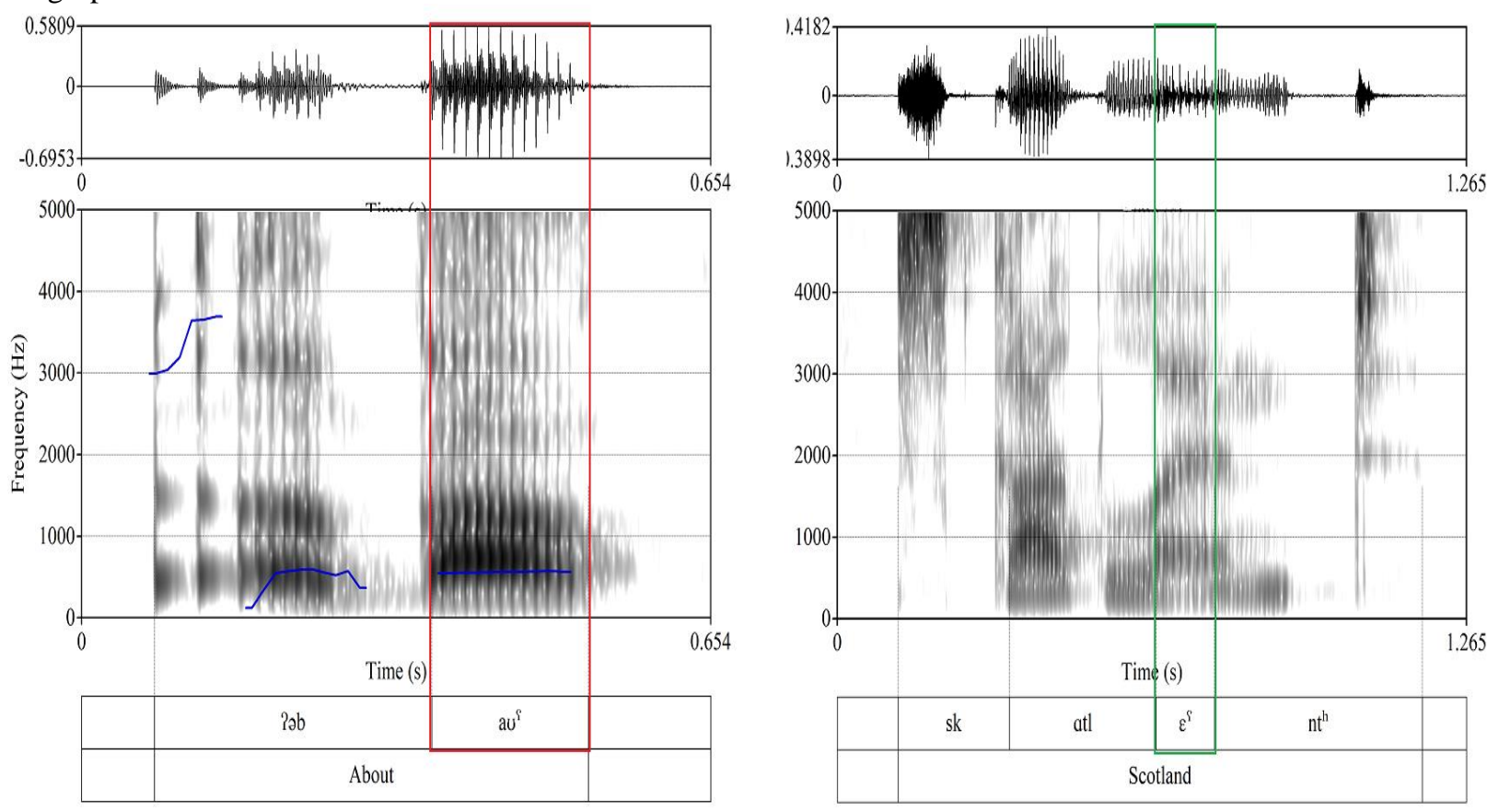

Fonte: os autores (2020).

$\mathrm{Na}$ laringalização, os pulsos glotais também possuem comportamento semelhante aos da oclusiva glotal, apresentando duração $>5$ milissegundos em toda extensão vocálica. Na sua realização, há um aumento do contato e da adução das pregas vocais. Esse processo reflete nas estrias verticais (observadas no espectrograma de 
banda larga), as quais apresentam maior duração, como mostra a Figura 3. Diferentemente da oclusiva glotal, a laringalização pode abranger um ou vários segmentos vozeados ao longo de uma palavra ou frase, como aponta Garellek (2015). Um parâmetro acústico adequado e robusto utilizado de forma consistente pela literatura para mensurar o grau de laringalização produzido por um falante/grupo de falantes é a Inclinação Espectral (spectraltilt - ST).

A ST, medida em $\mathrm{dB}$, representa o grau em que ocorre decaimento na intensidade em função do aumento da frequência. Segundo Jokinen \& Alku (2017), há na literatura várias maneiras de estimar e de modificar esse parâmetro na análise da fala em função de uma série de diferentes objetivos (extração da medida para comparação com outros dados, machine learning, etc). De acordo com Bird et al. (2019, p. 53-54), a mais comum é que a inclinação espectral representa a diferença entre o $2^{\circ}$ harmônico e o $1^{\circ}$, isto é, $\mathrm{ST}=\mathrm{H} 2-\mathrm{H} 1$. Isto significa que, quanto maior essa diferença, menor o valor da ST (uma vez que o $2^{\circ}$ harmônico terá amplitude menor do que o $1^{\circ}$ harmônico e assim por diante).

Gostaríamos de chamar atenção para alguns aspectos do fenômeno de laringalização. Sua produção, diferentemente da oclusiva glotal, não é um processo de alofonia entre um determinado som e outro, mas, pode estar relacionada a questões de diferentes ordens, tais como:

- Prosódico-estilísticas: e que resultam, acusticamente, em mudanças na trajetória da F0 e intensidade (decaimento brusco) e/ou na qualidade da voz do falante que a produz (voz creptante) como aponta Telles (2013), e/ou questões;

- Sociofonéticas/Sociolinguísticas: em que um determinado grupo social (as "Valley girls" - ou "patricinhas"), estratificadas como falantes estadunidenses de inglês/L1 do sexo feminino, faixa etária entre 15 e 25 anos de idade, tendo como local de origem cidades de prestígio do meiooeste nos Estados Unidos, como Los Angeles, San Franciso, dentre outras, e de classe social média/alta, laringalizam as vogais em sintagmas finais de orações assertivas, conforme asseveram Aronson (1990), Blyth et al (1990), Bucholtz et al (2007), Ritchart \& Arvaniti (2013) e Ritchart \& Arvaniti (2014). 
Quanto ao reforço glotal, este foi o único evento em que os dois grupos realizam de modo discreto e não significativo $\left(\chi^{2}=0,63\right.$ (1), $\left.\mathrm{p}=0,42\right)$. Em nossos dados, sua realização se deu a partir da sequência de uma vogal laringalizada e glotalizada, seguida de uma oclusiva alveolar, como mostra a Figura 4:

Figura 4: Porção à esquerda: forma de onda, espectrograma de banda larga, contorno de F0 (em azul) na produção do sintagma "a lot" (muito), formando um reforço glotal a partir da segunda metade laringalizada e glotalizada da vogal baixo-anterior [a] (contorno em vermelho) até a plosiva alveolar [ $\left.\mathrm{t}^{\mathrm{h}}\right]$, por um falante do grupo NAT. Porção à direita: forma de onda, espectrograma de banda larga na produção da palavra "shirt" (camisa) formando um reforço glotal a partir do $3^{\circ}$ terço laringalizado e glotalizado na vogal médio-central $[\Lambda]$ (contorno em verde) até a alveolar $[\mathrm{t}]$ por um falante do grupo BRA
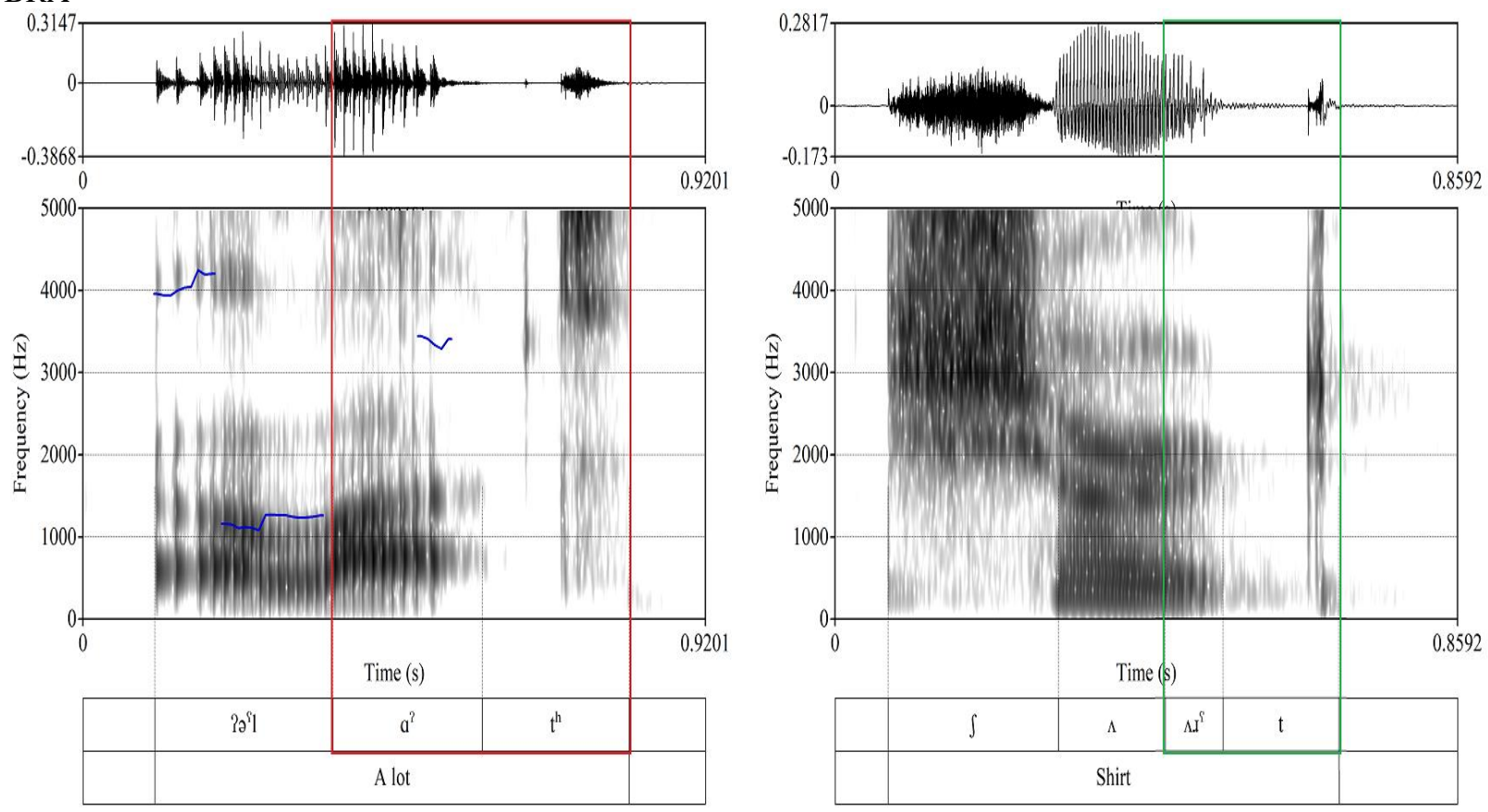

Fonte: os autores (2020).

Já o apagamento da oclusiva alveolar, como abordado anteriormente, foi realizado apenas pelos brasileiros. Além disso, o grupo realizou mais apagamentos do que a própria oclusiva glotal $(8,2 \%$ contra $3,3 \%)$. Esta não realização pode vir a ser um indício de uma tentativa de produção da oclusiva glotal em que, ao mesmo tempo, o falante mostra certa dificuldade em produzi-la.

Ademais, se levarmos em conta as características acústicas da oclusiva glotal e vogais laringalizadas, ou seja, valores mais baixos de energia espectral, por causa do decaimento da F0 (o que dificultaria a percepção/produção do brasileiro falante de 
inglês/L2), além da não consciência fonológica do segmento-alvo por parte do aprendiz, poderíamos, mesmo que de modo precoce, inferir que o apagamento sonoro da alveolar pode vir a ser uma tentativa de realização de nova categoria fonética na L2, devido ao seu contexto de aplicação (o som é apagado no mesmo ambiente em que ocorreria a produção da oclusiva glotal). Segundo Flege (1995), esta tentativa é ativada a partir do momento que não há a realização do gesto fonético original da L2 (a glotalização-t, em nossa pesquisa) mas, ao mesmo tempo, não há a realização de um parâmetro da L1 (a produção da oclusiva alveolar).

Vejamos, na Figura 5, como se dá a realização acústica do apagamento sonoro. Observemos que a continuidade do contorno da F0 (em azul dentro do espectrograma de banda larga) é uma das evidências da continuidade da vogal.

Figura 5: Forma de onda, espectrograma de banda larga, contorno da F0 (em azul) na produção da palavra "about" (sobre/em relação a) formando um apagamento sonoro no ditongo [av] (contorno em verde) por um falante do grupo BRA.

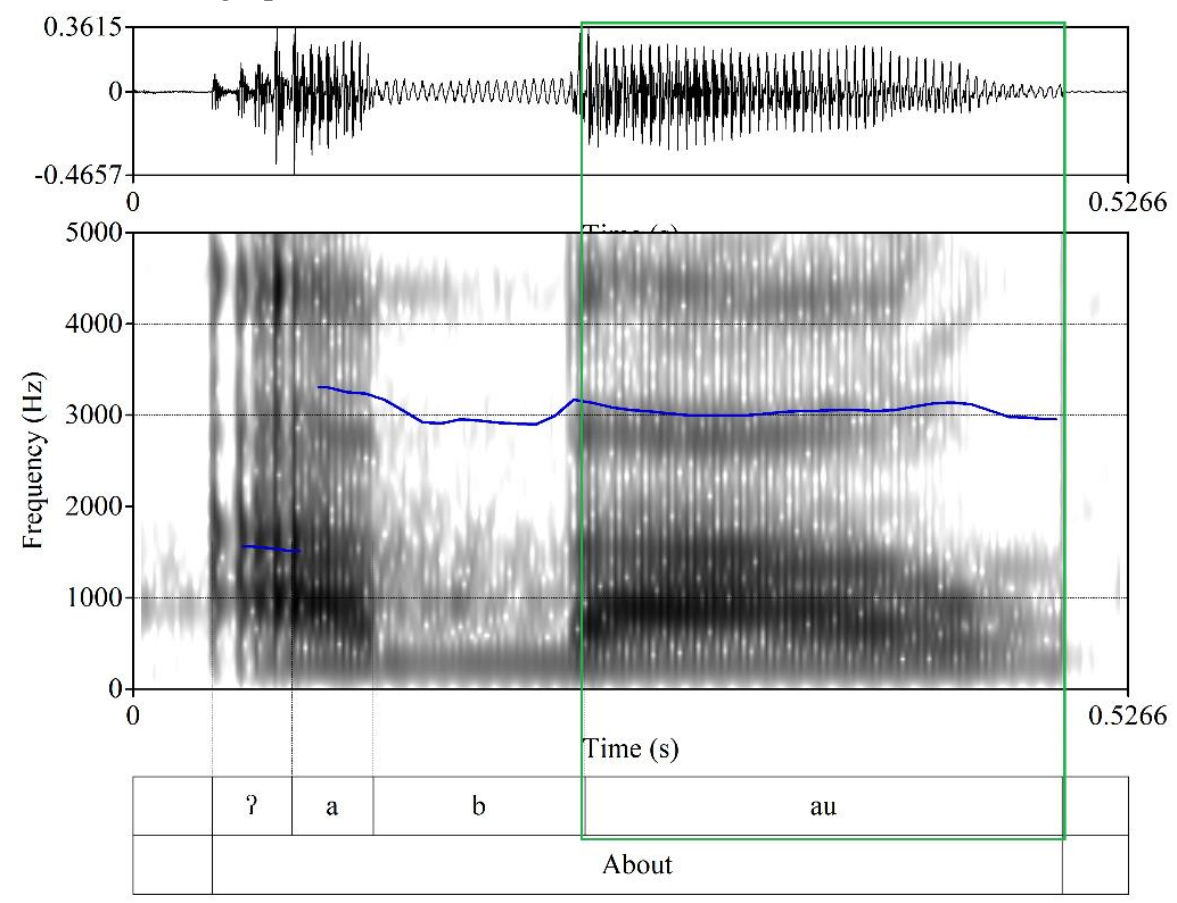

Fonte: os autores (2020)

A partir dos dados, até aqui apresentados, podemos inferir que:

- O grupo NAT realiza tanto a oclusiva glotal quanto a laringalização de modo significativamente maior do que o grupo BRA, o qual realiza a 
oclusiva alveolar significativamente maior do que ambos os fenômenos: oclusiva glotal e laringalização.

- Para o grupo NAT, os correlatos acústicos de duração, F0 e intensidade, apresentam valores maiores do que para o BRA. Por exemplo, a duração da laringalização nas vogais-gatilho (para glotalização) é de aproximadamente $\frac{1}{2}$ vs. $\frac{1}{3}$ da duração do grupo BRA. Por sua vez, o decaimento da F0 e intensidade, mensurados via inclinação espectral, apresentam valores menores para o grupo NAT ( $-34 \mathrm{~dB}$ vs. $-9 \mathrm{~dB})$. A inclinação espectral é um correlato robusto para identificação de esforço vocal e tipo de fonação dos falantes, segundo Jokinen \& Alku (2017, p. 327) e Bird et al. (2019, p. 54-55). Quanto menor este valor, mais glotalizado e/ou laringalizado é o alvo durante a produção (p. 327-328);

- O grupo NAT evita o uso de gestos fonéticos que necessitam de um "reforço" (ou de um esforço extra) posterior ao gesto de laringalização (o reforço glotal, por exemplo) e, por isso, a frequência baixa desta ocorrência;

- No grupo BRA, o reforço glotal ocorreu de modo semelhante ao NAT (discretamente com valores não significativos) como observado por alguns falantes (cf. Tabela 1, Gráfico 2). Vale lembrar que o reforço glotal é representado no espectrograma pela soma entre as realizações de laringalização seguida de uma oclusiva alveolar (cf. Figura 4). Mesmo com a percepção e produção de um gesto laríngeo, os participantes brasileiros buscam o reforço, ou seja, a produção da oclusiva alveolar, como ponto de apoio em função de uma não consciência fonológica plena de que a oclusiva alveolar pode ser substituída completamente por outro segmento (apenas a oclusiva glotal e/ou laringalização).

Observando as seções, dados e figuras até aqui apresentadas, vejamos, no Quadro 1, uma síntese das características acústicas dos fenômenos encontrados em nossa pesquisa. 
Quadro 1: Características acústicas dos fenômenos que nos deparamos em nossas análises.

\begin{tabular}{|c|c|}
\hline FENÔMENOS & CARACTERÍSTICAS ACÚSTICAS \\
\hline Oclusiva glotal & $\begin{array}{l}\text { Pulsos glotais longos (da ordem de } 10-16 \text { milissegundos), no final } \\
\text { do } 3^{\text {o }} \text { terço do som vocálico analisado, bem como F0 e intensidade } \\
\text { baixas. }\end{array}$ \\
\hline $\begin{array}{l}\text { Oclusiva } \\
\text { alveolar }\end{array}$ & $\begin{array}{l}\text { Pico de intensidade em frequências altas }(>7000 \mathrm{~Hz}) \text { com zonas de } \\
\text { aprisionamento, transigência e soltura bem definidas. }\end{array}$ \\
\hline Laringalização & $\begin{array}{l}\text { Pulsos glotais longos, em toda a extensão do som vocálico } \\
\text { analisado, com duração }>5 \text { milissegundos, bem como F0 e } \\
\text { intensidade baixas. }\end{array}$ \\
\hline Reforço glotal & $\begin{array}{l}\text { Processo com características semelhantes à sequência: } \\
\text { laringalização }+ \text { oclusiva alveolar. }\end{array}$ \\
\hline $\begin{array}{l}\text { Apagamento } \\
\text { sonoro }\end{array}$ & $\begin{array}{l}\text { Preservação das características acústicas da vogal em toda sua } \\
\text { extensão. }\end{array}$ \\
\hline
\end{tabular}

Fonte: os autores (2020).

\section{CONSIDERAÇÕES FINAIS}

Por meio do presente estudo, foi possível observar que os norte-americanos analisados produzem a oclusiva glotal em detrimento da oclusiva alveolar com significativa frequência. Ainda, nossas amostras apontam para outros fenômenos laríngeos, tais como: laringalização e reforço glotal, para ambos grupos BRA e NAT e apagamento da oclusiva alveolar apenas para o BRA. Nesse sentido, além da oclusiva glotal, a laringalização e o reforço glotal estão presentes em contexto de alofonia com a oclusiva alveolar.

Assim, diferentemente do grupo NAT, o BRA realiza o caminho inverso, produzindo significativamente mais a oclusiva alveolar do que a oclusiva glotal, o que atesta a nossa hipótese levantada no início da pesquisa: falantes brasileiros de inglês/L2 apresentam dificuldades no alcance da produção da oclusiva glotal. Ademais, as características acústicas da glotal contribuem para produção de outras categorias fonéticas, inclusive para o apagamento da oclusiva alveolar. 
Acreditamos que esse resultado, por parte dos brasileiros, está relacionado ao fato de que os falantes de inglês/L2, especialmente aqueles que não possuem a oclusiva glotal no inventário fonológico de sua L1, como é o caso dos informantes aqui analisados, tendem a confundi-la com uma omissão sonora, o que faz com que o aprendiz não a produza e tampouco a perceba. Isso, portanto, nos direciona a uma investigação perceptiva do segmento-alvo por parte dos aprendizes de inglês/L2.

Ainda, vale a pena destacar que, por ser um segmento produzido em uma região interna do trato vocal, a visualização de sua produção não é de fácil acesso, o que traz mais complexidades para o segmento, no tocante à aprendizagem de sua articulação por meio de uma instrução explícita. Concluímos, então, que a oclusiva glotal se configura como um som de natureza acústica e articulatória complexa, bem como perceptiva, dado que é um segmento de intensidade baixa, o que a torna um som fraco e pouco inteligível aos brasileiros.

Ademais, poderíamos inferir que os outros gestos laríngeos produzidos pelo BRA seriam uma tentativa da produção do fenômeno de glotalização-t, ainda que fora produzido significativamente pouco, preferindo a produção da oclusiva alveolar ou do apagamento desta.

Para trabalhos futuros, é possível verificar se os brasileiros percebem produções da oclusiva glotal, a partir de um teste de percepção. Além de averiguar se estes, após um treinamento metafonológico de como a oclusiva glotal pode ser articulada, produzem e/ou percebem de maneira significativa o segmento-alvo. Nesse sentido, percebemos a necessidade de dar continuidade aos estudos em glotalização-t com interface em L2, no intuito de contribuir com a literatura da oclusiva glotal no processo de ensino-aprendizagem, bem como com o ensino de pronúncia de inglês/L2 no Brasil.

\section{Referências}

ARONSON, Arnold. Clinical voice disorder: an interdisciplinary approach. 3. ed. New York: Theme Strattion, 1990.

BALAS, Anna. Glottal Stops Produced by Polish Native Speakers in Polish and English. In: Proceedings of The International Conference of Phonetic Sciences, 2011, Hong Kong, ICPhS XVII, 2011, p. 280-283. 
BARBOSA, Plínio; MADUREIRA, Sandra. Manual de fonética acústica experimental. Aplicações a dados do português. São Paulo: Cortez Editoria, 2015.

BIRD, Sonya; WANG, Qian; ONOSSON, Sky; BENNER, Allison. LING 380: Acoustic Phonetics Lab Manual. Victoria: University of Victoria, 2019

BLYTH, Carl; RECKTENWALD, Sigrid; WANG, Jenny. I'm like, "SayWhat?!": A New Quotative in American Oral Narrative. American Speech, v. 65, n. 3, p. 215-227, 1990.

BOERSMA, Paul; WEENINK, David. Praat: doing phonetics by computer (Version 6.0). Disponível em: <http//www.praat.org, 2019>. Acesso em: 20 de set. 2019.

BUCHOLTZ, Mary; BERNUDEZ, Nancy; FUNG, Victor; EDWARDS, L.; VARGAS, R. Hella Nor Cal or Totally So Cal?: The Perceptual Dialectology of California. Journal of English Linguistics, v.35, n. 4, p. 325-352, 2007.

COBACHO, Noèlia. The Increasing Use of t-glottalling in Received Pronunciation. 2018. 57f. Tese (Doutorado) - Universidade Autônoma de Barcelona, Barcelona, 2018.

DRUMMOND, R. Glottal variation in /t/ in non-native English speech: patterns of acquisition. English World-Wide, v. 32, n. 3, p. 280-308, 2011.

DUARTE, Mariane. Produção da oclusiva glotal [?] por falantes brasileiros de inglês como L2. 2018. 66f. Trabalho de Conclusão de Curso (Licenciatura em Letras - Inglês) - Universidade Estadual da Paraíba, Guarabira, 2018.

DUARTE, Mariane; SILVA JR., Leônidas. Produção da Oclusiva glotal[?] por falantes brasileiros de inglês como L2. In: Silva, Maria. et al. Rede de saberes. Campina Grande: ADUEPB, 2019, p. 473-492.

EDDINGTON. David.; TAYLOR. Michael. T-glottalization in American English. American speech. v. 84, n. 3, p. 298-214, 2009.

FARIS, Majda. The Glottal Stop in English: A Descriptive Study. Journal of the college of basic education. Al-Mustansyriah University, v. 15, n. 65, p. 97-100, 2010.

FLEGE, James. The production and perception of speech sounds in a foreign language. In: WINITZ, Harris. (Ed). Human Communication and Its Disorders: a review. Norwood: Ablex, 1988, p. 224-401.

FLEGE, James. Second Language Speech Learning: Theory, Findings and Problems. In: STRANGE, Winifred. Speech Perception and linguistic Experience: Issues in Cross-Language Research. Timonium: York Press, 1995, p. 233-277.

GARELLEK, Marc; SEYFARTH, Scott. Acoustic comparison of / $t$ / glottalization and phrasal creak. The Journal of the Acoustical Society of America, Los Angeles, USA, V. 139, n. 4, p. 1054-1058, 2016. 
GARELLEK, Marc. Perception of glottalization and phrase-final creak. The Journal of the Acoustical Society ofAmerica, Los Angeles, v. 117, n. 2, p. 822-831, 2015.

GROSJEAN, François. Bilingual: Life and Reality. Cambridge: Harvard University Press, 2010.

GROSJEAN, François; LI, Ping. The Psycholinguistics of Bilingualism. West Sussex: Willey-Blackwell, 2013.

HUSSIEN-SEID, Worku. Acoustic characterization of glottal stop and glottalized sounds in Amharicusing non-spectral methods of speech analysis. 2011. $133 \mathrm{f}$. Tese (Doutorado) - International Institute of Information Technology, Hyderabad, India. 2011.

ITO, Kikuyo; STRANGE, Winifred. Perception of allophonic cues to English word boundaries by Japanese second language learners of English. The Journal of Acoustic Society of America, v. 125, n. 4, p. 2348-2360, 2009.

JOKINEN, Emma; ALKU, Paavo. Estimating the spectral tilt of the glottal source from telephone speech using a deep neural network. The Journal of Acoustic Society of America. v. 141, n. 4, p. 327-330, 2017.

LIMA-GREGIO, Aveliny. A oclusiva glotal e laringalização em sujeitos com fissura palatina: Um estudo segundo abordagem dinamicista. 2011. $85 \mathrm{f}$. Tese (doutorado) Instituto de Estudos da Linguagem, Universidade Estadual de Campinas, Campinas. 2011.

MARINO, Viviane; BERTI, Larissa; LIMA-GREGIO, Aveliny. Características acústicas da oclusiva glotal associada à sequência de Pierre Robin: estudo de caso. Revista CEFAC. Campinas SP, v. 15, n. 2, p. 466-477, 2013.

MONTEIRO, Mariane; SILVA JR., Leônidas. Produção da glotalização /t/ por falantes de inglês como L1e L2. In: Congresso Nacional de Educação, 2017. João Pessoa, Anais do IV CONEDU, 2017, p. 1-12.

NESPOR, Marina; VOGEL, Irene. Prosodic Phonology: with a new foreword. Berlin: Mouton de Gruyter, 2007 [1986].

NORTON, Donna. Guide to English Phonetic System: Learn IPA Sounds in Phonetics. Custom Writing, 2017. Disponível em: 〈https://custom-writing.org/blog/phonetics〉. Acesso em: 10 jun. 2019.

OGDEN, Richard. An introduction to English phonetics. Edinburgh: Edinburgh University Press, 2009.

PURPURA, James. Oxford Online Placement Test (OOPT). Disponível em: <https://www.oxfordenglishtesting.com/>. Acesso em: 10 de ago. 2019. 
$\mathrm{R}$ Core Team. R: A language and environment for statistical computing. R Foundation for Statistical Computing, Vienna, Austria, 2019. ISBN 3-900051-07-0. Disponível: <https://www.r-project.org/>. Acesso em: 25 de set. 2019.

RITCHART, Amanda; ARVANITI, Amalia. Do we all speak like valley girls? Uptalk in Southern Californian English. In: 166th Acoustical Society of America Meeting, San Francisco, 2013, p. 1-3.

RITCHART, Amanda; ARVANITI, Amalia. The form and use of uptalk in Southern Californian English. Proceedings of Speech Prosody, v.7, n.1, p. 20-23, 2014.

Disponível em: <https://library.ithaca.edu/>. Acesso em: 12 de out. 2019.

SELINKER, Larry. Interlanguage. International Review of Applied Linguistics, v.10, p. 209-231, 1972.

SHINOHARA, Yasuaki; HUCKVALE, Mark; ASHBY, Michael. Differences in Glottal Stop Perception Between English and Japanese Listeners. In: Proceedings of The International Conference of Phonetic Sciences, Hong Kong, 2011, ICPhS XVII, 2011, p. $1830-1833$.

SILVA JR., Leônidas; BARBOSA, Plínio. Speech Rhythm of English As L2: an investigation of prosodic variables on the production of Brazilian Portuguese speakers. Journal of Speech Sciences. v. 8, n. 2, p. 37-57, 2019.

STETSON, Raymond. Motor Phonetics: A Study of Speech Movements in Action. 2. ed. Amsterdam: North Holland Publishing Co., 1951 [1928].

SUNDARA, Megha. Acoustic-phonetics of coronal stops: A cross-language study of Canadian English and Canadian French. The Journal of Acoustic Society of America, v. 2, n. 118, p. 1026-1037, 2005.

TRIOLA, Mario. Introdução à estatística: Atualização Da Tecnologia. Rio de Janeiro: LCT, 2014.

Recebido em: 28/08/2020

Aceito em: 25/09/2020

\footnotetext{
${ }^{1}$ Neste trabalho, utilizamos o acrônimo L2 como sinônimo de LE (língua estrangeira) em conformidade com a literatura fonética que trata da temática corrente (cf. ITO \& STRANGE, 2009; SHINOHARA et al., 2011; BALAS, 2012; NORTON, 2017; DUARTE, 2018; DUARTE \& SILVA JR., 2019; dentre outros), embora os trabalhos na área de Bilinguismo, de forma majoritária, utilizem os referidos acrônimos (L2 e LE) de modo distinto em que: L2 (ou La) se referem a uma segunda língua e LE, a língua estrangeira (cf. GROSJEAN, 2010; GROSJEAN \& LI, 2013).

${ }^{2} \mathbf{d B}=$ decibéis. A mensuração em unidades $\mathrm{dB}$ é afeita à percepção do ouvinte por ser manipulada em escala logarítmica (SILVA JR \& BARBOSA, 2019).
} 